\title{
The Impact of Consumer Innovativeness on the Intention of Clicking on SNS Advertising
}

\author{
Yingren Shi \\ School of Business Administration, South China University of Technology, Guangzhou, China \\ Email:abruzzi_shi@163.com
}

How to cite this paper: Shi, Y.R. (2018) The Impact of Consumer Innovativeness on the Intention of Clicking on SNS Advertising. Modern Economy, 9, 278-285. https://doi.org/10.4236/me.2018.92018

Received: January 19, 2018

Accepted: February 9, 2018

Published: February 12, 2018

Copyright $\odot 2018$ by author and Scientific Research Publishing Inc. This work is licensed under the Creative Commons Attribution International License (CC BY 4.0).

http://creativecommons.org/licenses/by/4.0/

\begin{abstract}
Consumer Innovativeness is considered to be an important factor that influences consumers' choice of new services. This paper uses technology acceptance model to study the impact of consumer innovativeness on SNS advertising click intention. The research results show that attitude has a significant impact on click intention; Consumer innovativeness significantly affects consumers' attitude towards SNS advertising through perceived usefulness/ perceived ease of use/perceived enjoyment, thereby significantly affecting the click intention of SNS advertising. This study explores the influence factors of SNS's click intention from the perspective of user's emotion, enlarges the application scope of TAM and enriches the existing research results.
\end{abstract}

\section{Keywords}

Consumer Innovativeness, SNS Advertising, TAM

\section{Introduction}

According to the statistics of the Chinese Statistics Bureau, the scale of Chinese netizens reached 731 million by the end of 2016. Among them, SNS applications have a user scale of 670 million, and the use rate is up to $91.1 \%$. SNS has become the most important network application in China [1].

The most important profit source of social networking applications is advertising. Compared with traditional advertising, SNS advertising has many natural advantages: SNS advertising is more accurate, and advertising forms are more diverse, and it can achieve real-time interaction with users. In this case, which factors can affect the user's intention to click on SNS advertising has become an important subject in the academic field.

\section{Literature Review and Research Hypothesis}

Davis [2] proposed the Technology Acceptance Model (TAM) based on Theory 
of Reasoned Action (TRA), TAM believes that the user's attitude to the information system will directly affect the user's intention, While the perceived usefulness and perceived ease of use will affect the users' attitude towards information system [2]. Perceived usefulness refers to the user's perception of the value of one thing, and the perceived ease of use refers to the perception that it is easy to get this value. Furthermore, as an external variable, the user characteristics can affect the user's perceived usefulness and perceived ease of use. TAM has a strong ability to predict the user's intention to use, and is widely used to study the user's intention to accept advertising. Xie (2015) used technology acceptance model to study the influence factors of users' acceptance of WeChat marketing. Bouwman et al. [3] used TAM to study users' willingness to accept contents pushed by operators, and achieved good prediction results. Therefore, this paper chooses the technology acceptance model as the basic model of the research.

However, there are still a lot of gaps in the current research, the traditional TAM is only studied from the characteristics of the technology itself, without taking into account the user's own emotional perception. Childers' [4] study found that in a social network scenario, emotional factors are more likely to affect the user's intention to use new service than technical factors. In addition, how consumer innovativeness affects the intention of clicking on SNS advertising, and the existing research has not fully explained. Therefore, based on perceived usefulness and perceived ease of use, this paper introduces perceived enjoyment to TAM, in order to improve the explanatory ability of the model in SNS context.

In order to attract users to click on advertising, SNS sites often entertaining with pictures, video, games and other ways to improve enjoyment of advertising content, Melody M Tsang [5] believes that enjoyment is the most important factor affecting the user on advertising attitude, Lin (2014) has proved that the enjoyment of advertising information has a positive impact on consumers' attitude and has a positive impact on advertising value, so this paper introduces perceived enjoyment into the model as an influence factor of user attitudes.

The concept of consumer innovativeness was first proposed by MIDGLEY \& DOWLING [6]. Later, a series of scholars defined the concept. Most research think that consumer innovativeness is a potential psychological characteristics of consumers that preferring new things. Consumer innovativeness is considered to be an intrinsic attribute of consumer, and will not change with the change of the situation. The research shows that higher innovative consumers prefer not only to new things, but also to the information of new products. The SNS advertising as a new form of advertising, usually also contains a large number of product information, it can well meet the user demand for new things and new product information, so consumer innovativeness is an important factor affecting intention of SNS advertising click.

Many research introduce consumer innovativeness into TAM, Lopez et al. (2008) empirical demonstrate that consumer innovativeness positive impact 
perceived usefulness of mobile service advertising [7]. Kuo and Yen [8] empirical demonstrate that consumer innovativeness can have positive impact on the perceived ease of use. SNS advertising through social data can accurate advertising, SNS advertising is usually directly displayed in SNS website, and consumers can obtain information of new products without additional cost of learning. When the consumer's innovativeness is higher, the high demand for new product information will improve the perceived of usefulness and ease of use. Based on the above analysis, this study proposes the following assumptions:

H1: Consumer innovativeness will positively impact perceived usefulness of SNS advertising.

$\mathrm{H} 2$ : Consumer innovativeness will positively impact perceived ease of use of SNS advertising.

Hirunyawipada and Paswan [9] demonstrated that the higher the consumer innovativeness leads to a higher perception of the enjoyment in new things. For SNS advertising, the higher innovative the consumer is, the more easy it is to perceive the enjoyment contained in the advertising content. Based on the above analysis, this study proposes the following assumptions:

H3: Consumer innovativeness will positively impact perceived enjoyment of SNS advertising.

The attitude of consumers to advertising is generally considered to be the subjective evaluation of consumer's preference for advertising. Fatim Stuart's [10] research shows that when the advertisement contains the information that the consumer needs, the advertise will be more acceptable. Eldridge and Ginter [11] research shows that compared with other forms of advertising, consumers' attitudes towards mobile phone text advertisements are more positive, because the accuracy of mobile text advertising is higher, and consumers' perceived usefulness of advertisements are higher. Based on the above analysis, this study proposes the following assumptions:

H4: Perceived usefulness will positively impact attitude of consumers to SNS advertising.

In the technology acceptance model, perceived ease of use is usually considered as an important factor affecting the user attitude. Aldas. Manzano et al. [12] has studied the intention of consumers to accept mobile shopping, shows that perceived ease of use significantly affects consumers' attitudes towards mobile shopping. Based on the above analysis, this study proposes the following assumptions:

H5: Perceived ease of use will positively impact attitude of consumers to SNS advertising.

Koufaris and Marios [13] add enjoyment to the model when studying TAM, and prove that the enjoyment can positively affect the user's attitude. Nowadays, advertisements usually use various ways to increase the enjoyment of advertisements and make consumers more pleasant to see advertisements. Ducoffe [14] studies show that consumers' perceived enjoyment will positively affect their attitudes. Based on the above analysis, this study proposes the following assump- 
tions:

H6: Perceived enjoyment will positively impact attitude of consumers to SNS advertising.

Both the Theory of reasoned action and the theory of planned behavior hold that people's attitude towards things will affect people's behavior intention. The positive attitude of consumers to SNS advertise will drive them to click on it. Based on the above analysis, this study proposes the following assumptions:

H7: The attitude of consumers to SNS advertising will positively impact click intention.

The research model in this article is shown in Figure 1.

\section{Empirical Research}

\subsection{Questionnaire Design}

This paper designs the questionnaire according to Churchill's [15] suggestion, and uses the structural equation model to test the model hypothesis. First of all, the original questionnaire was formed through literature review; secondly, the experts were invited to amend the questionnaire; then, the initial questionnaire was amended by a small scope survey. All the items were measured by the Likert 7 point scale, 1 means "very disagree", and 7 means "very agree".

In this survey, 380 questionnaires were sent out and 54 invalid questionnaires were eliminated, and 326 valid questionnaires were obtained. In the available samples, the proportion of men and women is generally the same, accounting for $54 \%$ and $46 \%$, respectively. The number of people under 26 years of age is $57 \%$, and the number of people using social networks many times a day is 291, accounting for $89 \%$ of the total number of samples. China Internet Network Information Center (CNNIC) report shows that China's Internet users are dominated by young users under the age of 30 , accounting for $60 \%$. This is in accordance with the proportion of the sample, indicating that the sample can represent the situation of Chinese netizens [1].

In this paper, Cronbach's $\alpha$ coefficient and composite reliability (CR) were used to test the reliability of the valid questionnaire, and the average variance extracted value (AVE) was used to test the validity of the valid questionnaire.

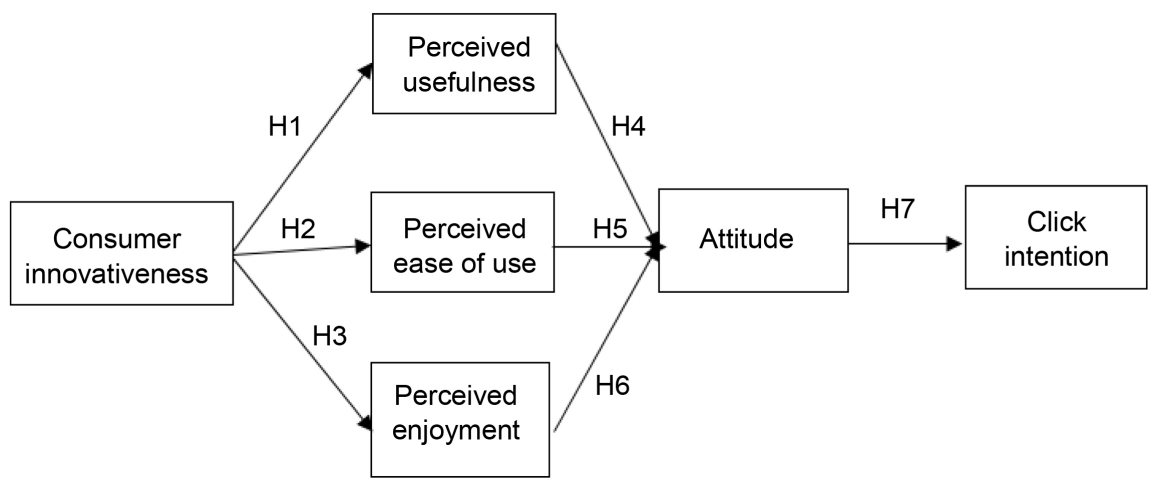

Figure 1. Research model. 
This article uses SPSS and Amos to test the sample data and display the results in the table below. Table 1 shows that standard factor loading of each factor in the model is more than 0.7, and the Cronbach's $\alpha$ and CR values of each factor are both higher than 0.8 , indicating that the reliability of the scale is good. The AVE values of perceived usefulness and attitude were 0.597 and 0.586 , slightly less than 0.6 , and the other factor were more than 0.6 , indicating that the questionnaire had good convergence validity.

Table 2 shows that the $\chi^{2} / \mathrm{df}$ of the model is 1.152 , less than 3 , and GFI and AGFI are 0.951 and 0.935 , which are all greater than 0.9; RMSEA is 0.028 , less than 0.08; CFI and NFI are 0.991 and 0.953, respectively, which are all larger than 0.9. These index values show that the model has a good fitting degree and discriminant validity to the data.

Table 1. Factor loading/AVE/CR and Cronbach's $\alpha$.

\begin{tabular}{cccccc}
\hline Variable & Item & factor loading & AVE & CR & Cronbach's $\alpha$ \\
\hline $\begin{array}{c}\text { Consumer } \\
\text { innovativeness }\end{array}$ & CI1 & 0.79 & 0.623 & 0.831 & 0.833 \\
& CI2 & 0.81 & & & \\
Perceived usefulness & CI3 & 0.78 & & & \\
& PU1 & 0.72 & 0.597 & 0.810 & 0.812 \\
& PU2 & 0.78 & & & \\
Perceived ease of use & PU3 & 0.82 & & & \\
& PEU1 & 0.85 & 0.712 & 0.869 & \\
PEU2 & 0.80 & & & \\
Perceived enjoyment & PEU3 & 0.82 & & & \\
& PE2 & 0.87 & 0.681 & 0.853 & \\
Attitude & PE3 & 0.72 & & & \\
& AT1 & 0.82 & 0.586 & 0.812 & 0.815 \\
& AT2 & 0.73 & & & \\
Click intention & AT3 & 0.72 & & & \\
& CW1 & 0.75 & 0.716 & 0.881 & \\
& CW2 & 0.85 & & & \\
& CW3 & 0.87 & & & \\
\hline
\end{tabular}

Table 2. Fitting degree and discriminant validity.

\begin{tabular}{ccc}
\hline Index & Recommended Value & Result \\
\hline$\chi^{2} / \mathrm{df}$ & $<3$ & 1.152 \\
GFI & $>0.9$ & 0.951 \\
$\mathrm{CFI}$ & $>0.9$ & 0.991 \\
$\mathrm{NFI}$ & $>0.9$ & 0.953 \\
AGFI & $>0.9$ & 0.935 \\
RMSEA & $<0.08$ & 0.028 \\
\hline
\end{tabular}




\subsection{Hypothetical Test}

The results of structural equation model analysis are given in Table 3. The relationship between consumer creativity and perceived entertainment is significant at the level of $p=0.01$. The relationship between perceived entertainment and attitude is significant at $\mathrm{p}=0.01$ level, while other paths are significant at $\mathrm{p}=$ 0.001 level. Consumer innovativeness has a significant impact on perceived usefulness, perceived ease of use, and perceived enjoyment, and $\mathrm{H} 1, \mathrm{H} 2$, and $\mathrm{H} 3$ are supported. Perceived usefulness, perceived ease of use, and perceived enjoyment had a significant impact on attitude, and H4, H5, and H6 were supported. Attitude has a significant impact on click intention, and $\mathrm{H} 7$ is supported.

\section{Conclusion and Revelation}

Most of the previous studies have focused on the impact of consumer innovativeness on the development of new products, but there are few studies on the willingness to click on SNS advertising. Based on the TAM, this paper makes an empirical study of the influence of consumer innovativeness on the intention of clicking on SNS advertising. The conclusion of this paper is as follows:

1) Consumer innovativeness has a significant impact on perceived usefulness, perceived ease of use, and perceived enjoyment:

Innovative consumers have a strong sense of innovation, and they tend to have a positive attitude to new things and are more likely to accept SNS advertising. They are eager for new experiences and are happy to click on the new form of advertising in SNS. Therefore, advertising companies should promote SNS advertising for innovative groups, and then drive more consumers to accept SNS advertising through their exemplary role.

2) Perceived ease of use significantly affects consumers' attitude to SNS advertising, and then affects the intention of clicking:

Perceived usefulness has an important impact on the intention of clicking on SNS advertising. The usefulness and ease of use of the information system will make the consumer more willing to use it. Therefore, advertising companies can enhance consumers' perceived usefulness by improving the amount of information contained in advertisements, so that consumers can accept and try to click

Table 3. SEM test result.

\begin{tabular}{cccccc}
\hline Hypothesis & Path & Estimate & S.E. & P & Result \\
\hline H1 & $\mathrm{CI} \rightarrow \mathrm{PU}$ & 0.27 & 0.087 & $* * *$ & supported \\
H2 & $\mathrm{CI} \rightarrow \mathrm{PEU}$ & 0.41 & 0.087 & $* * *$ & supported \\
H3 & $\mathrm{CI} \rightarrow \mathrm{PE}$ & 0.22 & 0.102 & $\star *$ & supported \\
H4 & $\mathrm{PU} \rightarrow \mathrm{AT}$ & 0.40 & 0.069 & $* * *$ & supported \\
$\mathrm{H} 5$ & $\mathrm{PEU} \rightarrow \mathrm{AT}$ & 0.33 & 0.067 & $* * *$ & supported \\
$\mathrm{H} 6$ & $\mathrm{PE} \rightarrow \mathrm{AT}$ & 0.21 & 0.042 & $* *$ & supported \\
$\mathrm{H} 7$ & $\mathrm{AT} \rightarrow \mathrm{CW}$ & 0.285 & 0.103 & $* * *$ & supported \\
\hline
\end{tabular}


SNS advertising.

3) Perceived enjoyment has a significant impact on consumers' attitude to SNS advertising:

TAM describes the reasons for the adoption of consumer mainly from the characteristics of information system, and ignores the emotional factors of consumer. In fact, perceived enjoyment is also an important factor affecting the willingness of consumers to click on SNS advertising. Consumers also pay attention to emotional value when they click on advertising. Therefore, advertising companies can increase consumers' perceived enjoyment by designing simple and vivid interfaces and enhancing interaction with consumers.

4) Consumers' attitudes significantly affect the intention of clicking on SNS advertising:

Consumers cannot understand the value of advertising before clicking, so the attitude of consumers to advertising has an important impact on the intention of clicking. Therefore, advertising companies should give full consideration to consumers' needs when putting SNS advertisements, and take corresponding strategies to increase consumers' satisfaction with advertisements.

\section{References}

[1] CNNIC. (2016) Statistical Report on Internet Development in China. China Internet Network Information Center (CNNIC), Beijing.

[2] Davis, F.D. (1989) Perceived Usefulness, Perceived Ease of Use, and User Acceptance of Information Technology. Society for Information Management and The Management Information Systems Research Center.

[3] Bouwman, H., Carlsson, C., Molina-Castillo, F.J., et al. (2007) Barriers and Drivers in the Adoption of Current and Future Mobile Services in Finland. Telematics \& Informatics, 24, 145-160. https://doi.org/10.1016/j.tele.2006.08.001

[4] Childers, T.L., Carr, C.L., Peck, J., et al. (2001) Hedonic and Utilitarian Motivations for Online Retail Shopping Behavior. Journal of Retailing, 77, 511-535. https://doi.org/10.1016/S0022-4359(01)00056-2

[5] Tsang, M.M., Ho, S.C. and Liang, T.P. (2004) Consumer Attitudes toward Mobile Advertising: An Empirical Study. M. E. Sharpe, Inc.

[6] Midgley, D.F. and Dowling, G.R. (1978) Innovativeness: The Concept and Its Measurement. Journal of Consumer Research, 4, 229-242. https://doi.org/10.1086/208701

[7] López-Nicolás, C., Molina-Castillo, F.J. and Bouwman, H. (2008) An Assessment of Advanced Mobile Services Acceptance: Contributions from TAM and Diffusion Theory Models. Information \& Management, 45, 359-364. https://doi.org/10.1016/j.im.2008.05.001

[8] Kuo, Y.F. and Yen, S.N. (2009) Towards an Understanding of the Behavioral Intention to Use 3G Mobile Value-Added Services. Computers in Human Behavior, 25, 103-110. https://doi.org/10.1016/j.chb.2008.07.007

[9] Hirunyawipada, T. and Paswan, A.K. (2006) Consumer Innovativeness and Perceived Risk: Implications for High Technology Product Adoption. Journal of Consumer Marketing, 23, 182-198. https://doi.org/10.1108/07363760610674310

[10] Bamba, F. and Barnes, S.J. (2007) SMS Advertising, Permission and the Consumer: 
A Study. Business Process Management Journal, 13, 815-829. https://doi.org/10.1108/14637150710834578

[11] Eldridge, M. and Ginter, R. (2001) Studying Text Messaging in Teenagers. CHI 2001 Workshop.

[12] Aldás-Manzano, J., Ruiz-Mafé, C. and Sanz-Blas, S. (2009) Exploring Individual Personality Factors as Drivers of M-Shopping Acceptance. Industrial Management \& Data Systems, 109, 739-757. https://doi.org/10.1108/02635570910968018

[13] Koufaris, M. (2002) Applying the Technology Acceptance Model and Flow Theory to Online Consumer Behavior. INFORMS.

[14] Ducoffe, R.H. (1995) How Consumers Assess the Value of Advertising. Journal of Current Issues \& Research in Advertising, 17, 1-18. https://doi.org/10.1080/10641734.1995.10505022

[15] Churchill, A. (1979) Paradigm for Developing Better Measures of Marketing Constructs. Journal of Marketing Research, 16, 64-73.

https://doi.org/10.2307/3150876 